\title{
Effects of microsurgical repair treatment on the clinical efficacy, complications, and flap follow-up scores of patients with exposed steel plates after surgery for foot and ankle fractures
}

\author{
Xianxue Xia, Zhiqiang Yang, Changgong Deng, Chaoming Song, Lu Chen, Peng Wei \\ Department of Orthopedics, Affiliated Hospital of North Sichuan Medical College, Nanchong, China \\ Contributions: (I) Conception and design: X Xia, P Wei; (II) Administrative support: Z Yang, C Deng; (III) Provision of study materials or patients: \\ X Xia, Z Yang, C Song, L Chen; (IV) Collection and assembly of data: All authors; (V) Data analysis and interpretation: X Xia, C Deng, C Song, L \\ Chen, P Wei; (VI) Manuscript writing: All authors; (VII) Final approval of manuscript: All authors. \\ Correspondence to: Peng Wei. Department of Orthopedics, Affiliated Hospital of North Sichuan Medical College, Nanchong, China. \\ Email: xiaxianxuexxx@163.com.
}

\begin{abstract}
Background: Treatment of exposed steel plates after surgery for foot and ankle fractures is complicated. This study aims to analyze the effects of microsurgical repair treatment on the clinical efficacy, complications, and flap follow-up scores of patients with exposed steel plates following foot and ankle fracture surgery.

Methods: Eighty-two patients with exposure of steel plates after surgical treatment for foot and ankle fractures in our hospital from March 2017 to March 2018 were included in this study. The patients were divided into a study group (43 patients who received microsurgical repair) and a control group (39 patients who received conventional repair surgery). We compared the clinical efficacy, complication rate, flap followup score, recovery of ankle-hindfoot function and ankle function before treatment and at 3 and 6 months after treatment, and patient satisfaction between the two groups.

Results: The clinical effectiveness rate in the study group was $95.35 \%$, which was higher than the control group $(76.92 \%)(\mathrm{P}<0.05)$. The flap appearance, texture, and elasticity scores in the study group were higher than those in the control group $(\mathrm{P}<0.05)$. After treatment, the American Orthopedic Foot and Ankle Society (AOFAS) score and Baird ankle score increased significantly in both groups, and reached a peak at 6 months after treatment. The peak scores of the study group were considerably higher than those of the control group at each period after treatment $(\mathrm{P}<0.05)$. The incidence of complications in the study group $(6.98 \%)$ was lower than the control group $(25.64 \%)(\mathrm{P}<0.05)$. Patient satisfaction was higher in the study group $(97.67 \%)$ than the control group $(79.49 \%)(\mathrm{P}<0.05)$.
\end{abstract}

Conclusions: Microsurgical repair of exposed steel plates after surgery for foot and ankle fractures has a significant clinical effect. It can improve the flap follow-up scores, accelerate healing of the ankle, improve aesthetics, and reduce the incidence of complications. It is therefore worthy of widespread use in clinics.

Keywords: Microsurgical repair; foot and ankle fracture; plate exposure; clinical efficacy; flap follow-up score

Submitted Sep 18, 2020. Accepted for publication Nov 06, 2020.

doi: 10.21037/apm-20-2018

View this article at: http://dx.doi.org/10.21037/apm-20-2018 


\section{Introduction}

Fractures of the foot and ankle refer to fractures of the articular surfaces both inside and outside of the ankle joint and under the tibia, which are mostly caused by indirect external forces and rarely caused by longitudinal extrusion (1). Patient will typically experience severe pain and swelling, leading to dysfunction and obvious phenotypic deformities. Therefore, there is a pressing need for timely anatomical fixation of the patient's intra-articular fracture and recovery of foot and ankle function (2). There is no unified treatment plan for the ankle joint, and surgical treatment is one of the important methods used to repair the foot and ankle joints. However, due to the structure of the foot and ankle, poor blood supply, local skin necrosis, soft tissue defects and other characteristics, some patients may experience exposed steel plates following surgery. This can often lead to different degrees of infection, and even secondary osteomyelitis, venous reflux obstruction, flap necrosis and other serious complications (3).

Treatment of exposed steel plates after surgery for fractures of foot and ankle is complicated, and presently, microsurgical repair treatment is a particularly advanced method used to clean the wound (4). Microsurgery is a subject of fine operations on fine tissues using optical magnification. And reports have indicated that bone microsurgery could help patients beautify their wounds, reduce the incidence of ulcers and infections, and promote healing (5). With the innovation and development of microsurgical repair technology, its value in the treatment of postoperative steel plate exposure for fractures of the foot and ankle is worthy of attention. This study explored the effects of microsurgical repair treatment on the clinical efficacy, complications, and flap follow-up scores of patients with exposed steel plates after surgery for foot and ankle fractures, and aimed to provide new ideas for clinical treatment. We present the following article in accordance with the STROBE reporting checklist (available at http:// dx.doi.org/10.21037/apm-20-2018).

\section{Methods}

\section{Inclusion and exclusion criteria}

A total of 85 patients with foot and ankle fractures with exposed steel plates after undergoing surgical treatment in our hospital from March 2017 to March 2018 were initially enrolled. All procedures performed in this study involving human participants were in accordance with the Declaration of Helsinki (as revised in 2013). This study was approved by Affiliated Hospital of North Sichuan Medical College (No. 2017ER (A) 034) and informed consent was taken from all the patients.

Inclusion criteria: (I) all patients underwent steel plate internal fixation; (II) with steel plate exposure; (III) all of them agreed to this study and signed informed consent; (IV) this study was approved by the medical Ethics Committee of our hospital. Exclusion criteria: (I) patients with liver, lung, kidney and other important organ damage or tumors; (II) patients with incomplete general information. (III) patients with severe mental illness that could not cooperate with the study.

\section{Surgical methods}

Patients in the control group were treated with conventional repair surgery. First, the dead bone and soft tissue were removed, and then the residual wound was repaired by skin flap transplantation. Following surgery, plaster was used to fix the position of the skin flap to prevent it from moving until the bones in the affected area were restored. Finally, the plaster was removed.

Patients in the study group received microsurgical repair treatment. Firstly, patients were administered epidural anesthesia, and then the wound, bone tissue, and active muscle were thoroughly cleaned and disinfected to remove necrotic skin tissue. The ventral derotation spondylodesis (VDS) materials were chosen according to the size of the wound to completely cover the wound. After 57 days of conventional negative pressure treatment, a flap repair operation was performed on the patient's original wound according to the specific conditions of the wound granulation tissue. During the operation, a microscope was used for debridement, and targeted hemostatic treatment was given postoperatively. The representative images of the patients with ankle fractures before treatment, the exposed state of steel plates and images after microsurgical repair and treatment were shown in Figure 1.

\section{Observation indicators}

\section{Clinical efficacy (6)}

The clinical efficacy of the surgery was evaluated according to the patient's wound healing, and was divided into cured, markedly effective, effective, and ineffective. Briefly, a cured clinical efficacy status refers to the flap having survived postoperatively, and the wound being closed at the first 

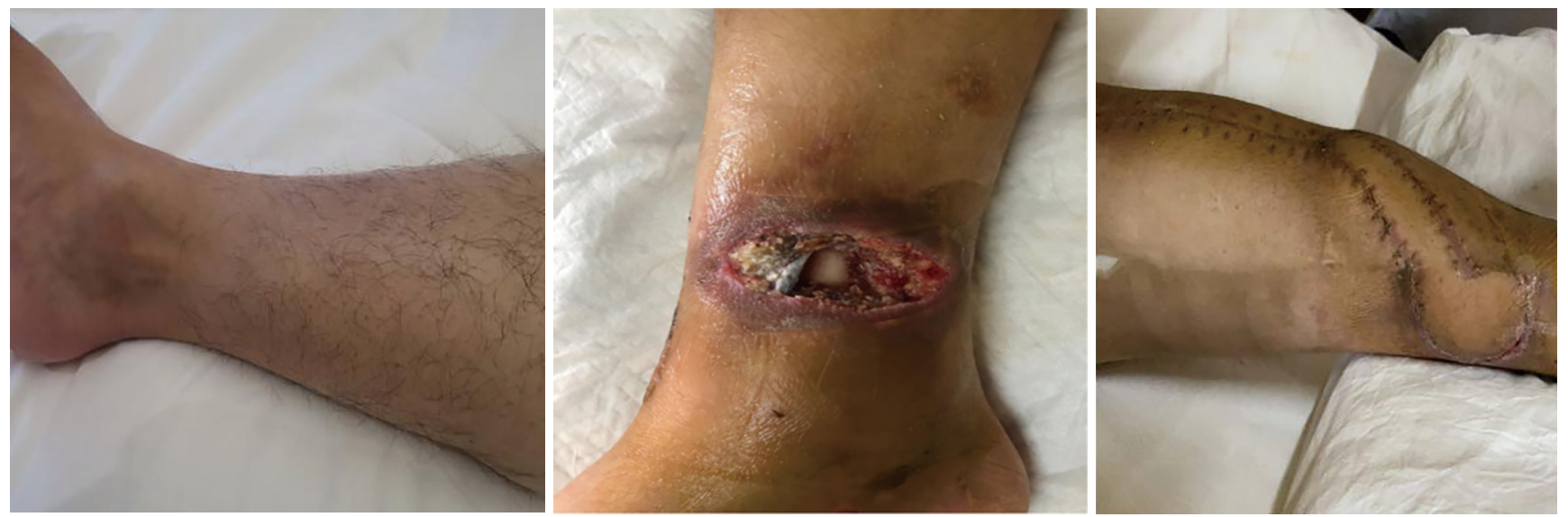

Figure 1 Patients with ankle fractures before treatment (left); the exposed state of steel plates (middle); after microsurgical repair and treatment (right).

stage. A markedly effective clinical efficacy status involves the following: the flap survives after the operation, the wound is significantly reduced, the soft tissue covers the exposed steel plate, the surface regrows fresh granulation tissue, and the wound heals smoothly after dressing change. An effective clinical efficacy status involves the following: there is postoperative necrosis of the partial flap with some steel plates still exposed, however, the exposed area is reduced, and the wound is healed following re-treatment. An ineffective clinical efficacy status refers to the flap being necrotic after the operation, and the exposed area of the steel plate does not decrease. The clinical effectiveness rate was calculated using the following equation: Clinical effectiveness rate $=($ cured + markedly effective + effective $) /$ number of cases $\times 100 \%$.

\section{Follow up}

One year after surgery (as of March 30, 2019), the patients were followed up. Using a self-administered questionnaire, the appearance, texture, and elasticity of the flap were scored by the patients under the guidance of the same nurse. The scoring range of each item was $0-100$ points, with a higher score indicating better recovery.

\section{Recovery}

Ankle-hindfoot function recovery and ankle joint recovery were assessed before treatment and at 3 and 6 months after treatment using the American Orthopedic Foot and Ankle Society (AOFAS) score and the Baird ankle score, respectively (7). The Ankle-hindfoot score ranges from 0 to 100 points, with higher scores indicating better the recovery of the ankle-hindfoot function. The Baird ankle joint score ranges from 0 to 100 points, with higher scores representing better ankle joint recovery. The assessments were performed by the same physician.

\section{Complications}

The occurrence of complications such as flap death, infection and necrosis, venous reflux obstruction, sinus formation, and osteomyelitis was observed.

\section{Satisfaction}

A self-administered satisfaction questionnaire was conducted to investigate patient satisfaction, and was divided into satisfaction, basic satisfaction, and dissatisfaction. The total satisfaction rate was calculated as: (satisfaction + basic satisfaction) $\times 100 \%$.

\section{Statistical methods}

Statistical analysis of all data in this study was performed using the SPSS22.0 software (IBM, USA). Measurement data (such as flap scores) were expressed as mean \pm standard deviation $(\bar{x} \pm \mathrm{s})$, and analyzed using $\mathrm{F} / t$ tests. Measurement data including clinical efficacy, postoperative flap survival, and satisfaction were also described as the mean \pm standard deviation $(\bar{x} \pm \mathrm{s})$, and were analyzed using the Chi-Square $\left(\chi^{2}\right)$ test. The difference was statistically significant when $\mathrm{P}<0.05$. 
Table 1 Comparison of the general data of the two groups

\begin{tabular}{|c|c|c|c|c|}
\hline General data & Study group $(n=43)$ & Control group $(n=39)$ & $t / \chi^{2}$ value & $P$ value \\
\hline Age (year) & $41.31 \pm 5.67$ & $42.25 \pm 5.61$ & 0.754 & 0.453 \\
\hline Sanders subtype (II/III/IV) & $25 / 18$ & $23 / 16$ & 0.006 & 0.939 \\
\hline $\begin{array}{l}\text { Fixed form (calcaneus plate screws/calcaneal plate } \\
\text { stainless steel screws) }\end{array}$ & $31 / 12$ & $29 / 10$ & 0.053 & 0.817 \\
\hline
\end{tabular}

Table 2 Comparison of clinical efficacy between the two groups [n (\%)]

\begin{tabular}{|c|c|c|c|c|}
\hline Efficacy & Study group $(n=43)$ & Control group $(n=39)$ & $\chi^{2}$ value & $P$ value \\
\hline Markedly effective & 19 (44.19) & $13(33.33)$ & & \\
\hline Effective & $7(16.28)$ & $7(17.95)$ & & \\
\hline Ineffective & $2(4.65)$ & $9(23.08)$ & & \\
\hline
\end{tabular}

Table 3 Comparison of flap appearance, texture, and elasticity between the two groups (scores)

\begin{tabular}{lcccc}
\hline Flap characteristic & Study group $(\mathrm{n}=43)$ & Control group $(\mathrm{n}=39)$ & $t$ value & $P$ value \\
\hline Flap appearance & $92.35 \pm 3.17$ & $73.64 \pm 5.49$ & 19.116 & $<0.001$ \\
Flap texture & $88.19 \pm 5.46$ & $75.43 \pm 5.19$ & 10.819 & $<0.001$ \\
Flap elasticity & $96.74 \pm 2.28$ & $76.89 \pm 4.96$ & 23.644 & $<0.001$ \\
\hline
\end{tabular}

\section{Results}

\section{General information}

A total of 85 patients with foot and ankle fractures with exposed steel plates following surgical treatment in our hospital from March 2017 to March 2018 were selected. Among them, one case was interrupted and two cases withdrew, and so, 82 cases were finally included. The patients were divided into a study group (43 cases) and a control group (39 cases) according to the different surgical methods that they received. There were no significant differences in the general information between the two groups $(\mathrm{P}>0.05$, Table 1$)$

\section{Clinical efficacy}

The total clinical effectiveness rate of the study group
(95.35\%) was significantly higher than the control group (76.92\%) $(\mathrm{P}<0.05$, Table 2).

\section{Flap appearance, skin texture, and elasticity scores}

Results showed that the flap appearance, texture, and elasticity scores in the study group were higher than those in the control group $(\mathrm{P}<0.05$, Table 3 and Figure 2).

\section{Comparison of AOFAS ankle-bindfoot score and Baird ankle scores between the two groups}

Before treatment, there were no differences in the AOFAS ankle-hindfoot and Baird ankle scores between the two groups $(\mathrm{P}>0.05)$. Meanwhile, after treatment, the AOFAS anklehindfoot and Baird ankle scores increased significantly in both groups and reached a peak at 6 months after treatment. The 


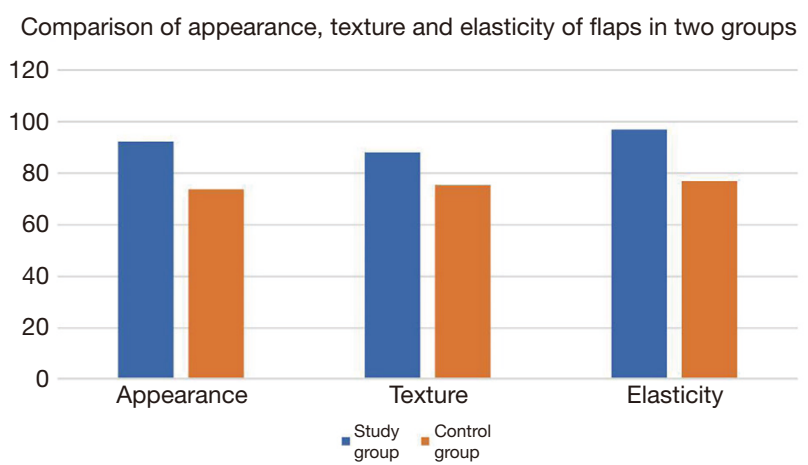

Figure 2 Flap appearance, texture, and elasticity in the two groups.
AOFAS ankle-hindfoot and Baird ankle scores of the study group were significantly higher than those of the control group at each period after treatment $(\mathrm{P}<0.05$, Table 4$)$.

\section{Complications and satisfaction}

The incidence of complications in the study group (6.98\%) was significantly lower than in the control group (25.64\%) $(\mathrm{P}<0.05)$. Also, the degree of patient satisfaction of the study group (97.67\%, 42/43) was higher than that of the control group $(79.49 \%, 31 / 39)(\mathrm{P}<0.05$, Table 5$)$.

Table 4 Comparison of ankle joint motion degrees between the two groups (scores, $\bar{x} \pm$ )

\begin{tabular}{|c|c|c|c|c|}
\hline Motion degree & Study group $(n=43)$ & Control group $(\mathrm{n}=39)$ & $t$ value & $P$ value \\
\hline Before treatment & $56.41 \pm 5.33$ & $56.53 \pm 5.22$ & 0.103 & 0.918 \\
\hline 3 months after treatment & $75.35 \pm 7.33^{*}$ & $69.14 \pm 6.52^{*}$ & 4.037 & $<0.001$ \\
\hline 6 months after treatment & $81.31 \pm 5.36^{*}$ & $75.44 \pm 5.47^{\star}$ & 4.905 & $<0.001$ \\
\hline Before treatment & $60.31 \pm 6.92$ & $61.17 \pm 6.51$ & 0.578 & 0.565 \\
\hline 3 months after treatment & $84.39 \pm 8.25^{\star}$ & $76.44 \pm 8.38^{\star}$ & 4.325 & $<0.001$ \\
\hline 6 months after treatment & $89.77 \pm 6.57^{\star}$ & $82.13 \pm 6.31^{*}$ & 5.359 & $<0.001$ \\
\hline
\end{tabular}

*, compared with the same group before treatment, $\mathrm{P}<0.05$.

Table 5 Comparison of the incidence of complications and the degree of patient satisfaction between the two groups [n (\%)]

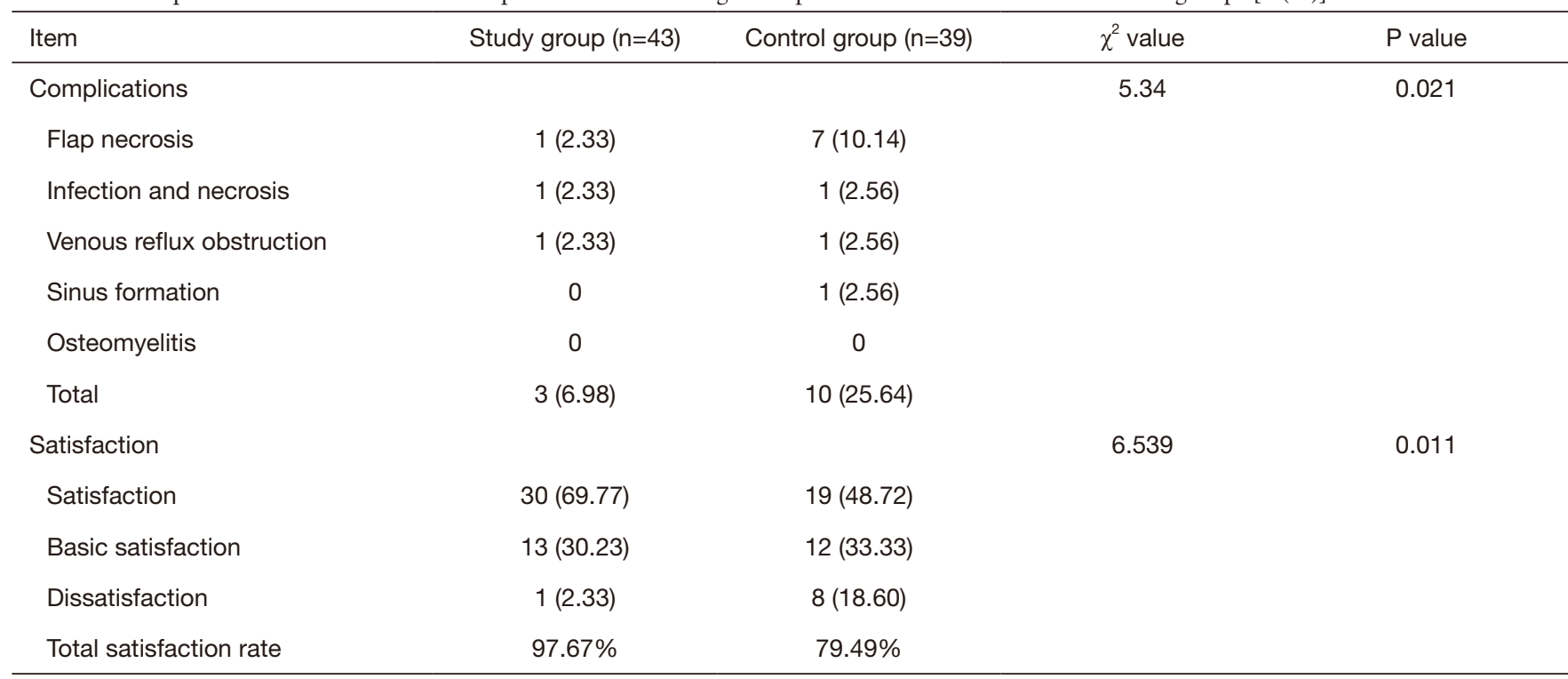




\section{Discussion}

The ankle joint is an important weight-bearing structure of the human body, and consists of the articular surfaces at the lower section of the tibia and fibula and the talus pulley. The ankle position is superficial, and bears much heavier weight and strength of movement than other joints. Furthermore, it lacks the protection of soft tissue and muscle. Therefore, it often forms open wounds coupled with skin peeling after being subjected to injury (8). In most cases, surgery is performed for the treatment of foot and ankle fractures. However, surgical intervention inevitably destroys the local blood supply, and internal fixation also increases the local volume, leading to incision-healing difficulties (9). Related studies have shown that postoperative steel plate exposure is likely to occur following surgery for foot and ankle fractures, which intensifies the pain and delays fracture healing. Therefore, the treatment of patients with postoperative exposure of steel plates has become a focus of clinical attention (10).

At present, treatment of exposed steel plates is difficult. This is because the treatment not only needs to repair the fixation problem of the fracture, but also control infection of the bone leakage wound and repair the wound. At the same time, exposure to the steel plates might cause serious infection of the wound surface, which has a great impact on the future recovery treatment (11). Therefore, active control of infection prior to repair and thorough debridement has become the prerequisite and basis for the successful repair of tissue flaps and internal fixation in the treatment of exposed steel plates (12).

Traditional treatment of exposed steel plates typically employs flap displacement to repair the wound. However, due to the occlusion of the internal fixation plate and incomplete cleaning of the necrotic tissue, a dead space may easily form, aggravating the infection and causing poor return of the skin flap or even necrosis (13). In recent years, microsurgical repair has become a mature application technology and is widely used in the treatment of numerous diseases. The working principle of microsurgical repair is to use a suction device to ensure cleanliness of the wound area, and to reduce the load of the tissue and blood vessels in the wound area, thereby stabilizing the blood pressure of the tissue, improving blood circulation, and providing higher oxygen content for skin tissue and muscles (14). In patients with exposed steel plates following surgery for foot and ankle fractures, the use of microsurgical repair can increase the efficiency of cleaning bacteria and impurities from the wound area and reduce postoperative infections, thereby promoting flap survival (15).

The results of this study showed that the total clinical effectiveness rate of the study group was significantly higher than that of the control group, and the incidence of complications in the study group was considerably lower than in the control group $(\mathrm{P}<0.05)$. These results indicate that, using microsurgery, the administration of skin flap transplantation is an effective method of repairing traumatic tissue, offering advantages such as a good curative effect and low complication rate. Also, the 1-year follow-up results showed that the flap appearance, texture, and elasticity scores in the study group were markedly higher than those in the control group $(\mathrm{P}<0.05)$. In addition, the study group exhibited substantially higher AOFAS ankle-hindfoot and Baird ankle scores than the control group at each period after treatment $(\mathrm{P}<0.05)$. This indicates that microsurgical repair can effectively promote skin tissue recovery, greatly improve the practicability of the flap and the function of ankle joint, improve the aesthetics of foot and ankle, and increase patient satisfaction (16).

In addition, clinical practice points out that the causes of plate exposure include trauma mechanisms, skin conditions, iatrogenicity and other factors. Therefore, the following issues should be paid attention to the treatment of patients with foot and ankle fractures to reduce the incidence of plate exposure: (I) Choose appropriate surgery method to avoid aggravating the blood supply disorder to the injured site; at the same time, choose reasonable materials to reduce the interference to the skin and soft tissue of the fracture; (II) Strengthen the tension-free suture during the operation, and when tension occurs, make a tension-reducing incision on both sides in time, and cover the steel plate properly; (III) Adequate drainage is required after the operation. For wounds with much oozing, the dressing must be changed frequently, and the drainage tube or drainage membrane should be properly extended. (IV) Strengthen postoperative anti-infection treatment and emphasize the sterility of medical staff to avoid nosocomial infection; if the patient has fever or increased secretions, bacterial culture should be done in time, and antibiotics need to be reasonably used when necessary.

In summary, microsurgical repair of exposed steel plates following surgery of foot and ankle fractures shows a significant clinical effect and is worthy of clinical promotion. It can improve the patient's flap follow-up score, accelerate the progress of ankle healing, improve aesthetics, and reduce the incidence of complications. The limitations 
of this study include the small sample size and the short follow-up time, and thus the results and conclusions of this study might not reflect the actual situation to some extent.

\section{Acknowledgments}

Funding: None.

\section{Footnote}

Reporting Checklist: The authors have completed the STROBE reporting checklist. Available at http://dx.doi. org/10.21037/apm-20-2018

Data Sharing Statement: Available at http://dx.doi. org/10.21037/apm-20-2018

Conflicts of Interest: All authors have completed the ICMJE uniform disclosure form (available at http://dx.doi. org/10.21037/apm-20-2018). The authors have no conflicts of interest to declare.

Ethical Statement: The authors are accountable for all aspects of the work in ensuring that questions related to the accuracy or integrity of any part of the work are appropriately investigated and resolved. All procedures performed in this study involving human participants were in accordance with the Declaration of Helsinki (as revised in 2013). This study was approved by Affiliated Hospital of North Sichuan Medical College (No. 2017ER (A) 034) and informed consent was taken from all the patients..

Open Access Statement: This is an Open Access article distributed in accordance with the Creative Commons Attribution-NonCommercial-NoDerivs 4.0 International License (CC BY-NC-ND 4.0), which permits the noncommercial replication and distribution of the article with the strict proviso that no changes or edits are made and the original work is properly cited (including links to both the formal publication through the relevant DOI and the license). See: https://creativecommons.org/licenses/by-nc-nd/4.0/.

\section{References}

1. Çayan S, Şahin S, Akbay E. Paternity Rates and Time to Conception in Adolescents with Varicocele Undergoing Microsurgical Varicocele Repair vs Observation Only: A Single Institution Experience with 408 Patients. J Urol
2017;198:195-201.

2. Çayan S, Akbay E. Fate of Recurrent or Persistent Varicocele in the Era of Assisted Reproduction Technology: Microsurgical Subinguinal Redo Varicocelectomy Versus Observation. Urology 2018;117:64-9.

3. Ono S, Sebastin SJ, Ohi H, et al. Microsurgical Flaps in Repair and Reconstruction of the Hand. Hand Clin 2017;33:425-41.

4. Schwartz C, Aster HC, Al-Schameri R, et al. Microsurgical clipping and endovascular treatment of middle cerebral artery aneurysms in an interdisciplinary treatment concept: Comparison of long-term results. Interv Neuroradiol 2018;24:608-14.

5. Mandell JC, Khurana B, Smith SE. Stress fractures of the foot and ankle, part 1: biomechanics of bone and principles of imaging and treatment. Skeletal Radiol 2017;46:1021-9.

6. Thorud JC, Mortensen S, Thorud JL, et al. Effect of Obesity on Bone Healing After Foot and Ankle Long Bone Fractures. J Foot Ankle Surg 2017;56:258-62.

7. Roizenblatt M, Grupenmacher AT, Belfort Junior R, et al. Robot-assisted tremor control for performance enhancement of retinal microsurgeons. Br J Ophthalmol 2019;103:1195-200.

8. Chaturvedi A, Mann L, Cain U, et al. Acute Fractures and Dislocations of the Ankle and Foot in Children. Radiographics 2020;40:754-74.

9. Jentzsch T, Hasler A, Renner N, et al. The V sign in lateral talar process fractures: an experimental study using a foot and ankle model. BMC Musculoskelet Disord 2017;18:284.

10. Boufi M, Patterson BO, Loundou AD, et al. Endovascular versus open repair for chronic type $\mathrm{B}$ dissection treatment: a meta-analysis. Ann Thorac Surg 2019;107:1559-70.

11. Stone MA, Flato RR, Pannell W, et al. Operatively Treated Talus Fractures: Complications and Survivorship in a Large Patient Sample. J Foot Ankle Surg 2018;57:737-41.

12. Vela FJ, Martínez-Chacón G, Ballestín A, et al. Animal models used to study direct peripheral nerve repair: a systematic review. Neural Regen Res 2020;15:491-502.

13. Kim JH, Patel S. Is It Worth Discriminating Against Patients Who Smoke? A Systematic Literature Review on the Effects of Tobacco Use in Foot and Ankle Surgery. J Foot Ankle Surg 2017;56:594-9.

14. Kihm CA, Camasta CA. Review of Drop Hallux: Assessment and Surgical Repair. J Foot Ankle Surg 2017;56:103-7.

15. O'Neill AH, Chandra RV, Lai LT. Safety and effectiveness of microsurgical clipping, endovascular coiling, and stent 
assisted coiling for unruptured anterior communicating artery aneurysms: a systematic analysis of observational studies. J Neurointerv Surg 2017;9:761-5.

16. Zhang F, Tian H, Li S, et al. Meta-analysis of two surgical

Cite this article as: Xia X, Yang Z, Deng C, Song C, Chen L, Wei P. Effects of microsurgical repair treatment on the clinical efficacy, complications, and flap follow-up scores of patients with exposed steel plates after surgery for foot and ankle fractures. Ann Palliat Med 2020;9(6):4089-4096. doi: 10.21037/apm20-2018 approaches for calcaneal fractures: sinus tarsi versus extensile lateral approach. ANZ J Surg 2017;87:126-31.

(English Language Editor: A. Kassem) 